

\title{
SURVIVAL OF CHILDREN WITH ACUTE LEUKAEMIA: A SINGLE CENTRE EXPERIENCE
}

\author{
Ariffin Nasir, Nor Fadhilah Zahari, Fahisham Taib, Norsarwany Mohamad
}

\begin{abstract}
Introduction: Acute leukaemia in children accounts for $25-30 \%$ of malignant diagnosis. Survival from acute leukaemia continue to improve. Treatment outcome depends on factors like gender, age at diagnosis, parental education, the initial total white cell count (TWC), cerebrospinal fluids (CSF) infiltration, immunophenotype and treatment response. Objectives: The objectives were to evaluate the survival of children with acute leukaemia who received chemotherapy and identify relevant factors. Methodology: The study was a retrospective record review at the Paediatric Oncology Unit, Hospital Universiti Sains Malaysia (Hospital USM). The data collected depending on pre-set research proforma from the year 1990 to 2010. Survival analysis of each type of leukaemia was completed using multiple Cox regression model. Results: A total of 334 cases were identified, only 283 patients received treatment at Hospital USM. There were 224 patients with acute lymphoblastic leukaemia (ALL) and 59 with acute myeloid leukaemia (AML). Overall survival (OS) rate at 3 months for ALL and AML were $89.3 \%$ and $72.9 \%$ respectively. The event-free survival (EFS) rate for ALL at 1, 3, and 5 years were $69.6 \%, 54.1 \%$ and $47.8 \%$ respectively. For AML, the EFS rate at 1,3 , and 5 years were $52.0 \%, 42.4 \%$ and $38.1 \%$ respectively. Multiple Cox regression model showed children's age at diagnosis and early response to steroid therapy were the most significant prognostic factors for ALL survival, whereas the spleen size and treatment protocol were the most significant prognostic factors for AML. Conclusion: Survival rate in this study was comparable to developing countries. ALL had better outcome compared to AML.
\end{abstract}

\section{Keywords:}

Survival Analysis, Acute Leukaemia, Acute Lymphoblastic Leukaemia, Acute Myeloid Leukaemia

\section{Introduction}

Acute lymphoblastic leukaemia representing approximately $80 \%$ of childhood leukaemia. The worldwide incidence has gradually increased annually. Untreated diseases are associated with early childhood mortality. The survival rate has improved significantly with the modern treatment modalities $[1,2]$. The survival rate of children with acute lymphoblastic leukaemia (ALL) is better than acute myeloid leukaemia (AML) with overall survival (OS) at $83 \%(95 \% \mathrm{Cl}$ : 80-85) for ALL, and 54\% (95\% Cl: 46-62) for AML in Northern Europe (3). A recent study stated that ALL survival rate has been improved significantly with 5-year-survival rate of $83.7 \%$ in 1990-1994 to 90.4\% in 2000-2005 [4]. In Malaysia, the 2-yearsurvival rate for ALL from 1980-1995 was $67 \%$ [5].
Received: 8 March 2020; Accepted revised manuscript: 11 May 2020

Published online: 14 June 2020
A 5-year-survival rate for ALL was the highest in age group 1-4 years old with $87 \%$ and at $60 \%$ for AML in the similar age group. Advancement in chemotherapy has been shown to favourably increase the curative rate in ALL. More than 95\% achieved complete remission (CR) with 5-year disease free survival rates at $63-83 \%$ [6]. The risk of relapse mostly depends on previously identifiable risk factors. Standard risk (SR) factors are age between 1-10 years old, initial TWC $<50 \mathrm{x}$ $10^{9} / \mathrm{L}$, absence of central nervous system and testicular involvement, T cell immunophenotype, M3 marrow on Day 15 or M2/M3 marrow on Day 36 and DNA index 1.16-1.6 (2). Risk stratification

Department of Paediatric, School of Medical Sciences, Universiti Sains Malaysia, 16150 Kubang Kerian, Kelantan Corresponding author: Assoc. Prof. Dr. Norsarwany Mohammad, Department of Paediatric, School of Medical Sciences, Universiti Sains Malaysia, 16150 Kubang Kerian, Kelantan.

Tel: +609-767 6540; Email: sarwany@usm.my 
has been modified into 4 groups as per Children's Oncology Group (COG) findings [7]. Younger age group and low TWC at diagnosis usually have better prognosis in AML patients. Children with Down Syndromes especially if the age less than 4 years old at the time of diagnosis tends to have a better outcome. The gender factor showed that females had a better survival rate than males $[2,8]$.

The objective of the study is to determine the survival of children with acute leukaemia (ALL and $A M L$ ) who received chemotherapy in Paediatric Oncology Unit at Hospital USM from the $1^{\text {st }}$ January $1990-31^{\text {st }}$ December 2010.

\section{Methods}

The study was conducted in Paediatric Oncology Unit at Hospital Universiti Sains Malaysia (Hospital USM), Kubang Kerian, Kelantan. Hospital USM is the pioneer for paediatric oncology in the East Coast of Peninsular Malaysia. Most of the patients originated from 3 neighbouring states (Kelantan, Terengganu and Pahang). These patients undergone chemotherapy and follow up treatment at Hospital USM. Patient records were retrieved retrospectively from ward registry for the diagnosis of ALL and AML. Confirmatory cases were from microscopic and cytological findings. Enrolled patients were those who started treatment from $1^{\text {st }}$ January 1990 until $31^{\text {st }}$
December 2010. Case notes were reviewed and information was obtained according to the proforma. Ethical approval was granted by the Universiti Sains Malaysia Ethical Committee (USMKK/PPP/JEPeM [238.4.(1.10)]) prior to the commencement of the study. Inclusion criteria were children with confirmed ALL or AML, receiving treatment at Hospital USM and age from newborn to 14 years old at the time of diagnosis. Exclusion criteria were cases with incomplete information such as treatment outcome, and patients who were transferred out to other hospital for continuation of chemotherapy.

Kaplan-Meier survival curves were used to calculate OS, event free survival (EFS) and log rank test were used to compare the survival curves of the subgroups. The factors investigated were age at the time of diagnosis, gender, immunophenotype, type of leukaemia, size of spleen and liver, early treatment response and CSF involvement. The proportion of events (resistance, relapse, death, complication) were compared using chi-square test. Univariate and Multivariate cox proportional hazard model were used to explore predictors of OS and EFS. The $p$ value of $<0.05$ is considered as significant. For the purpose of the study, definition below (Table 1) was used to calculate the parameters listed above.

Table 1: Table of definition

\begin{tabular}{ll}
\hline & Definitions \\
\hline 1. & Duration of survival is taken from the date of diagnosis \\
\hline 3. & Overall survival is taken from the time diagnosis to death or last contact \\
\hline Event free survival is time from diagnosis to the date of any event or to the date when patient was \\
confirmed to be well, at the date of censor which ever occurred first
\end{tabular}




\section{Result}

A total number of 334 acute leukaemia patients ( $A L L$ and $A M L)$ were identified during the study period ( $1^{\text {st }}$ January 1990 to $31^{\text {st }}$ December 2010). Out of that, 257 (77\%) patients were ALL and 77 (23\%) were AML. For ALL patients, 224 patients fulfilled the inclusion criteria and 33 were excluded. For AML patients, 59 were enrolled and 18 were excluded. There were 11 patients (19\%) identified as Down syndrome in this study. There were $60.1 \%$ of males and $39.9 \%$ of females in this study. The incidence of acute leukaemia was 1.5 times higher in males as compared to females. Majority of the patients were Malay ethnicity (97.4\%). About $21.2 \%$ of their parents had tertiary educational background and $23 \%$ had poor educational background (Table 2).

The common age group for ALL patients was 1.14.9 years $(55.8 \%)$ with mean age of 4.9 years old. Majority of them presented with TWC of less than $100.0 \times 10^{9} / \mathrm{L}(75.8 \%)$. Mean TWC at the time of presentation was $77.0 \times 10^{9} / \mathrm{L}$. There were $71.4 \%$ from B cell subtype, $20.5 \%$ from $T$ cell and 3.6\% from mixed lineage. Good early response to oral steroid was seen in $46.4 \%$ and $43.3 \%$ had poor early response. Most of the patients were stratified into the high risk treatment group, with $56.3 \%$ using EORTC-VHR protocol, 1.8\% using UKALL 97 (Regime B/C) and 2.2\% using Infantile Regime. About two third of ALL children completed chemotherapy (67\%). More than half of ALL patients (59.8\%) were alive at the end of the study period. For AML patients, $62.7 \%$ presented in the age group from 2.1 to 10 years old. The mean age at diagnosis was 6.4 years old. For the AML treatment, $59.3 \%$ of the patients received AML BFM 87 and $40.7 \%$ were on AML 12 UK Protocol. There were equal proportions of patients who completed chemotherapy, and who did not, which were $49.2 \%$ and $50.8 \%$ respectively. At the end of the study period, $40.7 \%$ were still alive (Table 3 ).

Table 2: Demographics profile of children with acute leukaemia registered in HUSM from 1990 - 2010

\begin{tabular}{|c|c|c|c|}
\hline Features & $\begin{array}{l}\text { All Patients }(n=283) \\
\text { no }(\%)\end{array}$ & $\begin{array}{l}\text { ALL }(n=224) \\
\text { no }(\%)\end{array}$ & $\begin{array}{l}\text { AML }(n=59) \\
\text { no }(\%)\end{array}$ \\
\hline \multicolumn{4}{|l|}{ Gender } \\
\hline Male & $170(60.1 \%)$ & $137(61.2 \%)$ & $33(55.9 \%)$ \\
\hline Female & $113(39.9 \%)$ & $87(38.8 \%)$ & $26(44.1 \%)$ \\
\hline \multicolumn{4}{|l|}{ Race } \\
\hline Malay & $276(97.4 \%)$ & $218(97.3 \%)$ & $58(98.3 \%)$ \\
\hline Chinese & $3(1.1 \%)$ & $3(1.3 \%)$ & 0 \\
\hline Indian & $1(0.5 \%)$ & 0 & $1(1.7 \%)$ \\
\hline Others & $3(1.1 \%)$ & $3(1.3 \%)$ & 0 \\
\hline \multicolumn{4}{|l|}{ Parental Education } \\
\hline Primary & 49 (17.3\%) & $41(18.3 \%)$ & $8(13.6 \%)$ \\
\hline Secondary & $109(38.5 \%)$ & $90(40.2 \%)$ & $19(32.2 \%)$ \\
\hline Tertiary & $60(21.2 \%)$ & $43(19.2 \%)$ & $17(28.8 \%)$ \\
\hline Missing data & $65(23 \%)$ & $50(22.3 \%)$ & $15(25.4 \%)$ \\
\hline
\end{tabular}


Table 3: Clinical profiles of children with ALL and AML

\begin{tabular}{|c|c|c|}
\hline Features & $\begin{array}{l}\text { ALL } \\
\text { n (\%) }\end{array}$ & $\begin{array}{l}\text { AML } \\
\mathrm{n}(\%)\end{array}$ \\
\hline \multicolumn{3}{|l|}{ Age at diagnosis } \\
\hline$\leq 1$ year & $7(3.1)$ & $8(13.6)^{*}$ \\
\hline$>1-4.9$ years & $125(55.8)$ & \\
\hline 5 - 9.9 years & $72(32.1)$ & $37(62.7)^{* *}$ \\
\hline$\geq 10$ years & $20(8.9)$ & $14(23.7)$ \\
\hline \multicolumn{3}{|l|}{ TWC at Diagnosis } \\
\hline$\leq 100 \times 10^{3} / \mu \mathrm{L}$ & $170(75.8)$ & $50(84.7)$ \\
\hline$>100.1 \times 10^{3} / \mu \mathrm{L}$ & $48(21.4)$ & $8(13.6)$ \\
\hline Missing data & $6(2.7)$ & $1(1.7)$ \\
\hline \multicolumn{3}{|l|}{ ALL Subtypes } \\
\hline B cell & $160(71.4)$ & \\
\hline T cell & $46(20.5)$ & \\
\hline Mixed & $8(3.6)$ & \\
\hline Missing data & $10(4.5)$ & \\
\hline \multicolumn{3}{|l|}{ AML Subtypes } \\
\hline Mo & & $0(0)$ \\
\hline M 1 & & $1(1.7)$ \\
\hline M 2 & & $14(23.7)$ \\
\hline M 3 & & $9(15.3)$ \\
\hline M 4 & & $11(18.6)$ \\
\hline M 5 & & $3(5.1)$ \\
\hline M 6 & & $10(16.9)$ \\
\hline M 7 & & $11(18.6)$ \\
\hline \multicolumn{3}{|c|}{ CSF involvement at Diagnosis } \\
\hline Yes & $9(4)$ & $0(0)$ \\
\hline No & $213(95.1)$ & $59(100)$ \\
\hline Missing data & $2(0.9)$ & 0 \\
\hline \multicolumn{3}{|l|}{ Liver size } \\
\hline$\leq 5 \mathrm{~cm}$ & $157(70)$ & $51(86.4)$ \\
\hline$>5 \mathrm{~cm}$ & $63(28.1)$ & 9 (13.6) \\
\hline Missing data & $4(1.9)$ & 0 \\
\hline \multicolumn{3}{|l|}{ Spleen size } \\
\hline$\leq 5 \mathrm{~cm}$ & $172(76.7)$ & $54(91.5)$ \\
\hline$>5 \mathrm{~cm}$ & $48(21.4)$ & $5(8.5)$ \\
\hline Missing data & $4(1.9)$ & 0 \\
\hline \multicolumn{3}{|l|}{ Treatment Protocol } \\
\hline EORTC_SR & $78(34.8)$ & \\
\hline EORTC_VHR & $126(56.3)$ & \\
\hline UKALL 97 Regime A & $11(4.9)$ & \\
\hline UKALL 97 Regime B/C & $4(1.8)$ & \\
\hline Infantile Regime & $5(2.2)$ & \\
\hline AML BFM 87 & - & $35(59.3)$ \\
\hline AML 12 UK Protocol & - & $24(40.7)$ \\
\hline \multicolumn{3}{|l|}{ Final Outcome } \\
\hline Alive & $134(59.8)$ & $24(40.7)$ \\
\hline Died & $90(40.2)$ & $35(59.3)$ \\
\hline
\end{tabular}

**Age group between 2- 10 years 


\section{Overall Survival Analysis}

In general, $55.8 \%$ of acute leukaemia patients were alive at the end of the study period. Immediate OS rate at 3 months after diagnosis was $85.9 \%$. The OS rate were $74.9 \%$ at 1 year, $61.7 \%$ at 3 years, $58.5 \%$ at 5 years, and $53.1 \%$ at 10 years. Overall mean survival time was 163.7 (147.5 - 180.0) months.

For ALL patients, $58.9 \%$ were alive at the end of the study period. Immediate OS rate at 3 months after diagnosis was $89.3 \%$. OS rate for ALL was $77.7 \%$ at 1 year, $66.9 \%$ at 3 years, $63.5 \%$ at 5 years, and $57.3 \%$ at 10 years after diagnosis. Overall mean survival time was 176.3 (158.5 - 194.1) months. For $A M L, 40.7 \%$ of patients were alive at the end of the study period. Immediate OS rate at 3 months was $72.9 \%$ after diagnosis. OS rate for AML was $59.3 \%$ at 1 year, and $41.4 \%$ at 3, 5 and 10 years respectively Overall median survival time was 20 (1.4 - 38.5) months. In our study, ALL had better OS rate compared to $\mathrm{AML}$, which was statistically significant ( $p$-value $<0.001)$.
In general, about $41.3 \%(n=117)$ of patients who were diagnosed with acute leukaemia did not experience any events at the end of study period. The above figure showed overall median survival time was 40 (13.0-67.0) months. Overall EFS rate was $66.0 \%$ at 1 year after diagnosis, $51.2 \%$ at 3 years, $45.6 \%$ at 5 years and $38.7 \%$ at 10 years. For ALL alone, $42.4 \%(n=95)$ patients had no event at the end of study period. The median survival time for ALL was 48 (19.5- 76.4) months. EFS rate for ALL was $69.6 \%$ at 1 year after diagnosis, $54.1 \%$ at 3 years, $47.8 \%$ at 5 years and $39.8 \%$ at 10 years. For AML, about $37.3 \%(n=22)$ patients had no event at the end of study period. The median survival time for AML was 16 (5.6- 26.0) months. EFS rate for AML was $52.5 \%$ at 1 year after diagnosis, $42.4 \%$ at 3 years, $38.1 \%$ at 5 years and $30.5 \%$ at 10 years. EFS rate was better in ALL as compared to $A M L$, with $p$ value 0.039 . Figure 1 showed the OS and EFS for children with ALL and AML using Kaplan- Meier model.
OS



EFS

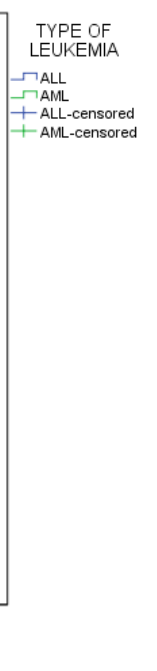

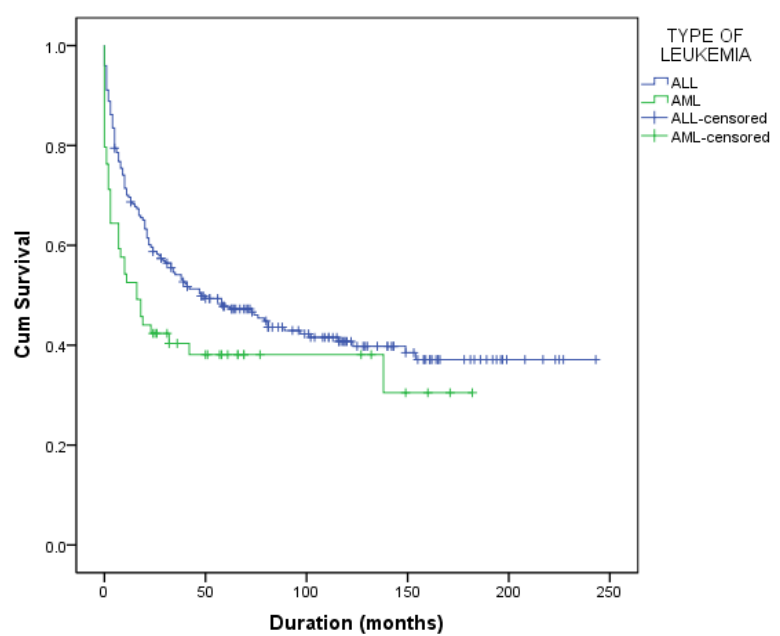

Figure 1: Kaplan- Meier estimates of OS and EFS for children with ALL and AML in Hospital USM

Males had better survival outcome as compared to females (42.4\% vs $30.8 \%)$. Median survival time was 16 months ( $95 \% \mathrm{Cl}: 0.00-53.12)$ for males and 16 months (95\% Cl: 1.00 - 30.99) for females. EFS rate at 10 years after diagnosis for females were $33.0 \%$, and $24.7 \%$ after 15 and 20 years respectively. Whereas for males, the EFS rates at 10,15 and 20 years were similar at $42.0 \%$ after the diagnosis.
Relapse was one of the main concern for both ALL and $\mathrm{AML}$ patients. The most common site of relapse was isolated bone marrow (BM) findings in both cases. BM relapse occurred in 52 children with ALL and 14 children with AML. There were 7 cases with CNS relapse, 1 for testicular relapse and 3 for both bone marrow and testicular relapse in ALL patients. For bone marrow and CNS relapse, $7 \mathrm{ALL}$ cases and $1 \mathrm{AML}$ case were identified. 
Simple Cox regression analysis that showed poor prognostic factors for ALL in this study were age group, aged 10 years old and above, high TWC at the time of diagnosis (more than $100.0 \times 10^{9} / \mathrm{L}$ ), CSF involvement at diagnosis, poor or undetermined early response to oral steroid and those in high risk group. Hazard ratio was high in children more than 10 years (HR 3.07; 95\% Cl: 1.74 - 5.44). For other prognostic factors, the hazard ratio was high; in children aged 0.1 to 1.0 year (HR 2.99; $95 \% \mathrm{Cl}$ : 1.19 - 7.45); aged 5.0 to 9.9 years old (HR 1.52, 95\% Cl: 1.04 - 2.23); TWC more than $100.0 \times 10 \%$ L (HR 1.669; 95\% Cl: 1.11- 2.49); CSF involvement at diagnosis (HR 2.368; 95\% Cl: 1.15 4.85); poor early response to steroid (HR 1.546; $95 \% \mathrm{Cl}: 1.06$ - 2.24); undetermined early response to oral steroid (HR 2.548; 95\% Cl: $1.32-4.98$ ); and high risk treatment group (HR 1.564; 95\% Cl: 1.08 - 2.25).
In multiple Cox proportional hazard model, it showed children's age at diagnosis and early response to steroid therapy were the significant prognostic factors for our ALL survival. There was increased risk of death or relapse ALL in children aged $\geq 10$ years old $(95 \% \mathrm{Cl}: 1.70-5.54 ; \mathrm{p}<$ $0.001)$, followed by children aged $\leq 1$ year old (95\% Cl: $1.16-7.35 ; p=0.020)$ and undetermined early response $(95 \% \mathrm{Cl}: 1.18-4.44 ; \mathrm{p}=0.014)$. For $\mathrm{AML}$, multiple Cox proportional hazard model (backward LR) showed spleen size and treatment protocol were the most significant prognostic factors for our AML survival. There was an increased risk of death or relapse AML in children with spleen size $>5 \mathrm{~cm}$ below subcostal margin (95\% Cl: 1.47 - 11.48; $p=0.007$ ), followed by children who treated with AML BFM 87 protocol (95\% Cl: 1.33 - 6.26; $p=0.007$ ) (Table 4).

Table 4: Prognostic factors for poor outcome in children with ALL and AML

\begin{tabular}{|c|c|c|c|}
\hline Variable & $\begin{array}{r}\text { Crude Hazard ratio } \\
\qquad(95 \% \mathrm{Cl})\end{array}$ & $\begin{array}{c}\text { Wald statistic } \\
\text { (df) }\end{array}$ & p-value \\
\hline \multicolumn{4}{|l|}{ ALL } \\
\hline \multicolumn{4}{|l|}{ Age } \\
\hline$>1.0-4.9$ years & 1.0 & & \\
\hline$\leq 1 \quad$ years & $2.29(1.16,7.35)$ & $5.21(3)$ & 0.022 \\
\hline $5.0-9.9$ years & $1.51(1.02,2.25)$ & $4.26(3)$ & 0.039 \\
\hline$\geq 10$ years & $3.07(1.70,5.54)$ & 13.99(3) & $<0.001$ \\
\hline \multicolumn{4}{|l|}{ Early Response } \\
\hline Good & 1.0 & & \\
\hline Poor & $1.34(0.91,1.97)$ & $2.25(2)$ & 0.133 \\
\hline Undetermined & $2.29(1.18,4.44)$ & $6.04(2)$ & 0.014 \\
\hline \multicolumn{4}{|l|}{ AML } \\
\hline \multicolumn{4}{|l|}{ Spleen } \\
\hline$\leq 5 \mathrm{~cm}$ & 1.0 & & \\
\hline$>5 \mathrm{~cm}$ & $4.01(1.44,11.12)$ & $7.08(1)$ & 0.008 \\
\hline \multicolumn{4}{|l|}{ Treatment Group } \\
\hline AML 12 UK & 1.0 & & \\
\hline AML BFM 87 & $2.89(1.33,6.26)$ & $7.30(1)$ & 0.007 \\
\hline
\end{tabular}

AML 12 UK and AML BFM 87 refer to treatment strategy used for acute myeloid leukaemia (AML)

\section{Discussion}

Majority of our patients (95\%) originated from the East part of Peninsular Malaysia. Relapse in ALL occurred within 2 to 3 years after diagnosis, but for $\mathrm{AML}$, it was within a year after diagnosis. The number of patients with acute leukaemia has significantly increased from the year 1990 to 2010. The increment has gone up to more than $50 \%$ in the year $1990-1994$ to the year 1995 1999 , followed by 20 - 25\% increment in the year 2005 - 2010. For AML, the rate of increment from 1990 - 1994 and 1995 - 1999 was about $25 \%$ and further increased up to $50 \%$ in year 2000 - 2004 
and 2005 - 2010. The Hospital USM Oncology Unit has been set up in 1990 to accept referrals from neighbouring states which led to increase in number of cases. Many parents delayed seeking treatment, especially in 1990 - 1994 and seeking for an alternative therapy after clinical and laboratory diagnosis [9]. In literature, the incidence of acute leukaemia has increased due to various environmental factors such as chemical, benzene and air pollutants [10].

The demographic variables for ALL and AML, such as gender and age distribution in our study, were almost similar to other reported studies [1,3]. The incidence in male was 1.5 times higher than female [11]. Kelantanese were homogenously inhabited by Malay and Siamese and reflected in our demographic capture that the predominant race group was Malay (97.4\%), followed by Siamese (1.1\%), Chinese (1.1\%) and Indian (0.5\%). For the ALL subtype, B-cell subtype was the commonest followed by T-cell and mixed (biphenotype). These findings were almost similar as reported previously $[12,13,14]$. For $A M L, F A B$ classification was used and majority of patients had M2, M3, M4, M6, and M7, which was similar to Goubin et al. [1].

Treatment protocol has evolved from year 1990 to 2010 for both ALL and AML. The EORTC protocol was changed to UKALL protocol in ALL. Response to steroid, TWC at presentation $>100 \mathrm{x}$ $10^{9} / \mathrm{L}$, age $\geq 10$ years at diagnosis, T-cell subtype, CSF involvement at diagnosis and male gender were considered a high risk group. Unfortunately, minimal residual disease (MRD) and cytogenetics tests were not performed locally as part of the risk assessment. Those who died were due to acute event such as septicaemia in 108 patients (87\%), followed by intracranial bleeding in 10 cases (8\%) and major complications such as disseminated intravascular coagulation (DIVC) in 6 cases (5\%).

\section{Overall Survival Rates for ALL and AML}

The immediate OS rate for acute leukaemia in Hospital USM at 3 months after diagnosis was $85.9 \%$. For ALL, immediate OS rate at 3 months after diagnosis was $89.3 \%$. The immediate OS rate for AML at 3 months after diagnosis was $78.0 \%$. Overall median survival time was $20(95 \% \mathrm{Cl}$ : 1.4 38.5) months. ALL had better OS rate compared to AML. These finding were also comparable to the other studies in developing countries $[2,5,15,16]$ but considered lower to developed countries [13].

\section{Event Free Survival (EFS) for ALL and AML}

There were a few reasons for relatively lower survival of both ALL and AML in our study compared to developed countries. Our patients' cohort had different biological features. There was higher incidence of T-cell subtype (20.5\%) compared to EORTC 58881 trial which possessed 7.6-15\% patients with T-cell immunophenotype $[1,2,17,18]$. Many patients from our cohort had high TWC at the time of diagnosis. There were $21.4 \%$ with initial TWC $>100 \times 10^{9} / \mathrm{L}$ compared to $13 \%$ in EORTC 58881 study [17], and 19\% in ALLBFM 90 protocol study [19]. Thirty-seven percent of our patients had initial TWC $>50 \times 10^{9} / \mathrm{L}$. The rate of CSF involvement at presentation was also high (4\%) as compared to other studies $1.8-2 \%$ $[5,19]$. Hence, lower proportion of children with good early response at $46.4 \%$.

Lower survival rates in AML patients were seen in our study. The subtype M7 (18.6\%) were higher compared to other study (6 - 10.6\%) [1]. Cytogenetic analysis was not routinely performed and the data was not available for analysis except for Down Syndrome group. Simple Cox regression analysis showed significant prognostic factors for ALL were older age at diagnosis, higher TWC count at diagnosis, CSF involvement at diagnosis, poor and undetermined early response and high risk treatment group. In multiple Cox regression analysis, only older age group at diagnosis and undetermined early response were the significant factors. For simple Cox regression analysis of $A M L$, the significant prognostic factors were bigger spleen size at diagnosis and treatment group AML BFM 87. These 2 factors showed significant results after multiple logistic regression analysis.

The present study possessed a few limitations. Firstly, the total numbers of sample size are low. About $15 \%(n=51)$ cases were excluded due to multiple reasons. As this was a retrospective record review, poor documentation in the case notes resulted in the unavailability of important information for the study. Secondly, prognostic factors such as cytogenetic abnormality especially in AML were not analysed in this study due to unavailability of cytogenetic test in the first 10year study period. We did not investigate the MRD status after induction course. Other factors such as determination of platelet, haemoglobin counts, uric acid level, nutritional status during treatment, risk of getting infection and the distance from hospital could be considered important information for data capture in our settings. These factors might contribute to 
treatment interruption which lead to poor disease outcome. Thirdly, obtaining the data retrospectively were challenging due to extensive data search in each patient treated for leukaemia. It was time consuming to recover the data accuracy for one study subject.

It is hoped that with more passionate explanation by the treating specialist, more awareness about leukaemia among family members and availability of cytogenetic study will improve patients'survival.

\section{Conclusion}

Survival rate in this study was comparable to developing countries but remained low compared to developed countries. ALL had better outcome compared to AML. Majority of ALL cases relapsed within 2 to 3 years, in contrast to AML relapse occurred within a year after diagnosis. Multifactorial causes have been attributed to the lower survival in our area.

\section{Acknowledgement}

We would like to thank the Paediatric department, paediatric oncology unit, and Hospital USM for allowing to conduct the research project. Not forgotten to Prof Nor Sa'adah Bachok, Dr Farzana Alam and Dr Safiyya Amaran for the guidance during the statistical analysis of the project. We would like to acknowledge the grant 1001/ PPSP/8012292 for this publication.

\section{References}

[1] Goubin A, Auclerc MF, Auvrignon A, Patte C, Bergeron C, Hemon D, et al. Survival in France after childhood acute leukemia and NonHodgkin's Lymphoma (1990- 2000). European Journal of Cancer. 2006;42:534- 41.

[2] Bonilla M, Gupta S, Vasquez R, Fuentes RL, deReyes G, Ribeiro $R$, et al. Predictors of outcome and methodological issues in children with acute lymphoblastic leukemia in El Salvador. European Journal of Cancer. 2010;46:3280-6.

[3] Coebergh JWW, Reedijk AMJ, de Vries E, Martos C, Jakab Z, Steliarova-Foucher E, et al. Leukemia incidence and survival in children and adolescents in Europe during 19781997. Report from the Automated Childhood
Cancer Information System Project. European Journal of Cancer. 2006;42:2019-36.

[4] Hunger SP, Loh ML, Whitlock JA, Winick NJ, Carroll WL, Devidas $M$, et al. Children's Oncology Group's 2013 Blueprint for Research: Acute Lymphoblastic Leukemia. Pediatr Blood Cancer. 2013; 60(6):957-63.

[5] Ng SM, Lin HP, Ariffin WA, Zainab AK, Lam SK, Chan LL. Age, sex, haemoglobin level, and white cell count at diagnosis are important prognostic factors in children with acute lymphoblastic leukemia treated with BFMtype protocol. Journal of Tropical Pediatrics. 2000;46:338-43.

[6] Schrappe $M$, Reiter A, Ludwig WD, Harbott J, Zimmermann M, Hiddemann $W$, et al. Improved outcome in childhood acute lymphoblastic leukemia despite reduced use of anthracyclines and cranial radiotherapy: results of trial ALL-BFM 90. German-AustrianSwiss ALL-BFM Study Group. Blood. 2000;95(11):3310-022.

[7] Schultz KR, Pullen DJ, Sather HN. Risk and response-based classification of childhood Bprecursor acute lymphoblastic leukemia: A combined analysis of prognostic markers from the Pediatric Oncology Group (POG) and Children's Cancer Group (CCG). Blood. 2007;109:926-35.

[8] Johnston T, Lightfoot TJ, Simpson G, Roman E. Childhood cancer survival: A report from United Kingdom Childhood Cancer Study. The International Journal of Cancer Epidemiology, Detection, and Prevention. 2010;3:659- 66.

[9] Othman A, Nasir A, Mohammad N, Taib F. The use of Malay traditional healers in childhood cancer. Malaysian J Paediatr Child Health. 2016;20:26-37.

[10] Hagopian A, Lfta R, Hassan J, Davis, Mirick D, and Takaro T. Trends in childhood leukemia in Basrah, Iraq, 1993 - 2007. American Journal of Public Health. 2010;6: 1081-7.

[11] Kaatsch P, Steliarova-Foucher E, Crocetti E, Magnani C, Spix C, Zambon P. Time trends of cancer incidence in European children (19781997): Report from the Automated Childhood Cancer Information System Project. European Journal of Cancer. 2006;42: 1961 - 1971.

[12] Sazawal S, Gurbuxani S, Bhatia K, Khattar A, Raina V, Arya LS, et al. Incidence, clinical characteristics and early treatment outcome in Indian patients of childhood acute lymphoblastic leukemia with ALL-1 gene rearrangement. Leukemia Research. 2001;25: $693-8$. 
[13] Desandes E, Berger C, Tron I, Demeocq F, Bellec S, Blouin P, et al. Childhood cancer survival in France, 1990 - 1999. European Journal of Cancer. 2008;44:205-15.

[14] Soyer OU, Aytac S, Tuncer A, Cetin M, Yetgin $\mathrm{S}$, Sekerel BE. Alternative algorithm for LAsparaginase allergy in children with acute lymphoblastic leukemia. J Allergy Clin Immunol. 2009;123(4):895-9.

[15] Kaspers GJ, Creitzig U. Pediatric acute myeloid leukemia: International progress and future directions. Leukemia. 2005;19:2025-9.

[16] Quah TC, Sun L, Chew FT, Yeoh A, Lee BW. Survival of childhood leukemia in Singapore. Med Pediatr Oncol. 1996;26(5):318-24.

[17] Sirvent N, Suciu S, Rialland X, Millot F, Beniot $Y$, Plantaz D, et al. Prognostic significance of the initial cerebro-spinal fluid (CSF) involvement of children with acute lymphoblastic leukemia (ALL) treated without cranial irradiation: Results of European Organization for Research and Treatment of Cancer (EORTC) Children Leukemia Group study 58881. European Journal of Cancer. 2011;47:239-47.

[18] Plasschaert SLA, Kamps WA, Vellenga E, de Vries EGE, de Bont ESJM. Prognosis in childhood and adult acute lymphoblastic leukemia: a question of maturation? Cancer Treatment Review. 2004;30:37-51.

[19] Sackmann-Muriel F, Felice MS, Zubizarreta PA, Alfaro E, Gallego M, Rossi J, et al. Treatment result in childhood acute lymphoblastic leukemia with modified ALLBFM 90 protocol: lack of improvement in high-risk group. Leukemia Research. 1999;23:331-40. 